\title{
The Burden of COVID-19 in People Living with HIV: A Syndemic Perspective
}

\author{
Stephanie Shiau ${ }^{1} \cdot$ Kristen D. Krause $^{2,3} \cdot$ Pamela Valera $^{4} \cdot$ Shobha Swaminathan ${ }^{5,6} \cdot$ Perry N. Halkitis $^{1,2,4}$
}

Published online: 18 April 2020

○) Springer Science+Business Media, LLC, part of Springer Nature 2020

\begin{abstract}
The emergence of the novel coronavirus disease known as COVID-19 creates another health burden for people living with HIV (PLWH) who face multiple morbidities and may be at heightened risk for severe physical health illness from COVID19. Our abilities to address these morbidities in PLWH must be considered alongside the socially-produced burdens that both place this population at risk for COVID-19 and heighten the likelihood of adverse outcomes. These burdens can affect the physical, emotional, and social well-being of PLWH and interfere with the delivery of effective healthcare and access to HIV treatment. We posit that a syndemic framework can be used to conceptualize the potential impact of COVID-19 among PLWH to inform the development of health programming services.
\end{abstract}

Keywords HIV $\cdot$ COVID-19 $\cdot$ Syndemic $\cdot$ Health care $\cdot$ Antivirals $\cdot$ Psychosocial burdens

\section{Introduction}

In March 2020, the Centers for Disease Control and Prevention (CDC) highlighted people living with HIV (PLWH) as a population that may be at heightened risk for severe physical health illness from the new coronavirus disease known as COVID-19 compared to the general population [1]. This risk in PLWH is predicated on potential interactions between COVID-19, HIV, and other risk factors for COVID-19 complications such as diabetes and hypertension that are common in PLWH, potential interference with care

Stephanie Shiau

stephanie.shiau@rutgers.edu

1 Department of Biostatistics and Epidemiology, Rutgers School of Public Health, Piscataway, NJ, USA

2 Center for Health, Identity, Behavior \& Prevention Studies, Rutgers School of Public Health, Newark, NJ, USA

3 Department of Health Behavior, Society, and Policy, Rutgers School of Public Health, Rutgers School of Public Health, Newark, NJ, USA

4 Department of Urban-Global Health, Rutgers School of Public Health, Newark, NJ, USA

5 Department of Medicine, Infectious Diseases Practice, New Jersey Medical School, Newark, NJ, USA

6 Infectious Diseases Practice, University Hospital, Newark, NJ, USA and treatments, and high rates of socially-produced burdens in the form of violence, stigma, discrimination, isolation, and hate experienced by PLWH [1,2]. As such, a syndemic framework provides a meaningful and robust paradigm to understand the impact of COVID-19 disease in PLWH and to develop health programming services for PLWH in light of the COVID-19 pandemic.

A syndemic is defined as two or more epidemics interacting synergistically to produce an increased burden of disease in a population [3]. In this perspective, infection with severe acute respiratory syndrome coronavirus 2 (SARS-Cov-2), the virus responsible for COVID-19, is assumed to function in tandem with a myriad of health challenges faced by PLWH, including HIV itself, chronic non-communicable diseases, mental health burden, substance abuse, and other infections, all of which are catalyzed by biological, behavioral, psychosocial and structural drivers of disease as posited by Halkitis et al. $[4,5]$. Such synergies are even greater in older PLWH, who also are at higher risk for COVID-19-related mortality [6-8]. Over the last two decades, the extant literature has provided ample evidence to support the veracity of a syndemic framework along the developmental continuum $[4,5,9,10]$ and across time [11], which is notably a biopsychosocial perspective of health and disease $[12,13]$.

To understand the manifestation of COVID-19 in the lives of PLWH, it must be viewed alongside HIV and other health conditions that already exist in this population. 
These mutually reinforcing health conditions constitute a syndemic for PLWH $[4,14,15]$. Here, we discuss how HIV and medical comorbidities, including the co-occurrence of a broad range of diseases [16], may function synergistically to fuel COVID-19 disease in a syndemic [17]. Moreover, we address the drivers of such syndemics, namely the social and economic inequalities, including but not limited to socially produced psychological conditions (i.e., psychosocial burdens) and healthcare access.

\section{Comorbidities and COVID-19 in People Living with HIV}

Effective antiretroviral therapy (ART) has prolonged the lifespan of PLWH. In the United States, 1.2 million people are living with HIV. Of these, more than $50 \%$ are $50+$ years of age, and many physical complications related to long-term ART use and aging have arisen [18-21]. Older PLWH, in particular, have a higher risk of non-communicable comorbidities, including diabetes, hypertension, cardiovascular disease, and chronic lung disease than uninfected individuals of similar age [22-25]. Putative mechanisms for these comorbidities include aging itself and chronic inflammation caused by HIV and/or ART [26]. Epidemiologic evidence suggests that both older age and a number of comorbidities, including hypertension, diabetes, and chronic obstructive lung disease, are risk factors for severe COVID-19 disease [27]. While limited data are available on COVID-19 and HIV-coinfection as of early April 2020 [28-30], and on the potential protective effects of HIV antivirals [1,30], the interaction between these comorbidities nonetheless lends itself to an understanding through a syndemic framework [31]. Expression of the angiotensin-converting enzyme 2 (ACE2), identified as a crucial factor that facilitates SARSCoV-2 virus to bind and enter host cells, is substantially increased in patients with diabetes and hypertension, who are often treated with ACE inhibitors and angiotensin II type-I receptor blockers [32]. Further, there is a concern that individuals with severe immunodeficiencies, such as HIV, may be at risk for a severe course of COVID-19 disease.

Older PLWH may not be the only members of the HIV seropositive population at risk for the negative health sequelae of COVID-19. Given recent developments that have shown the vulnerability of those ages 18-49 to COVID-19 [33], younger PLWH may also be at heightened risk for mortality due to COVID-19 complications. Such risk is predicated on the fact that PLWH under age 50 are both less likely to be diagnosed (and in effect more likely to be immunocompromised) and also less likely to access and be retained in care, yielding viral suppression of a mere $37 \%$ on those age 25-34 [34].

\section{Psychosocial Conditions and COVID-19 in People Living with HIV}

The psychosocial conditions which fuel these interlocking health epidemics [35] are central for both understanding the drivers of severe COVID-19 infection in PLWH and for developing effective medical and public health interventions as shown in Fig. 1. PLWH have an increased likelihood of mental health burden, illicit drug use, and other STIs [36-38], all catalyzed by psychosocial burdens experienced at elevated rates in marginalized populations including sexual and gender minorities, racial and ethnic minorities, and/or the poor and underserved. While there is no standard set of psychosocial factors that are prescribed $[13,39]$, burdens such as medical mistrust, loneliness [4, 40], stigma [41], and hopelessness [42] have been implicated in the propagation of disease. In fact, at the Infectious Diseases Practice (IDP) at the New Jersey Medical School in Newark, where we collaborate, clinical staff who are managing patients via telephone conversations amidst the COVID-19 pandemic indicate many individuals are extremely stressed, anxious, and unable to sleep.

Physical distancing or social isolation recommended by the CDC to reduce the spread of COVID-19 may add additional burden to already highly burdened lives. Physical distancing is described as avoiding crowds, canceling large events, closing schools, staying at and working from home; these measures have been shown to reduce the rate of new COVID-19 infections. However, we know very little about how physical distancing enforced by a pandemic such as COVID-19 continues to impact PLWH. Older PLWH already experience heightened rates of loneliness and social isolation [43, 44], compromising their social and emotional well-being and health in light of social distancing efforts [45], albeit sound epidemiological principles inform such efforts. Diminished neurocognitive functioning and heightened mental health burden evidence in older PLWH may impede effective self-care [46]. Moreover, for individuals from underserved communities and communities of color who constitute the majority of patients we see at the IDP, physical distancing may not be possible due to financial conditions or work circumstances. Economic disparities, associated with worse health conditions and underlying health conditions [47], likely explain higher death rates due to COVID-19 noted in communities of color [48].

These and other conditions are those internally-produced states imparted by social conditions of social injustice and health inequity. In this view, societal conditions such as discrimination, poverty, and homophobia drive the development of these internalized states that interfere with the ability for both people and populations to address their 


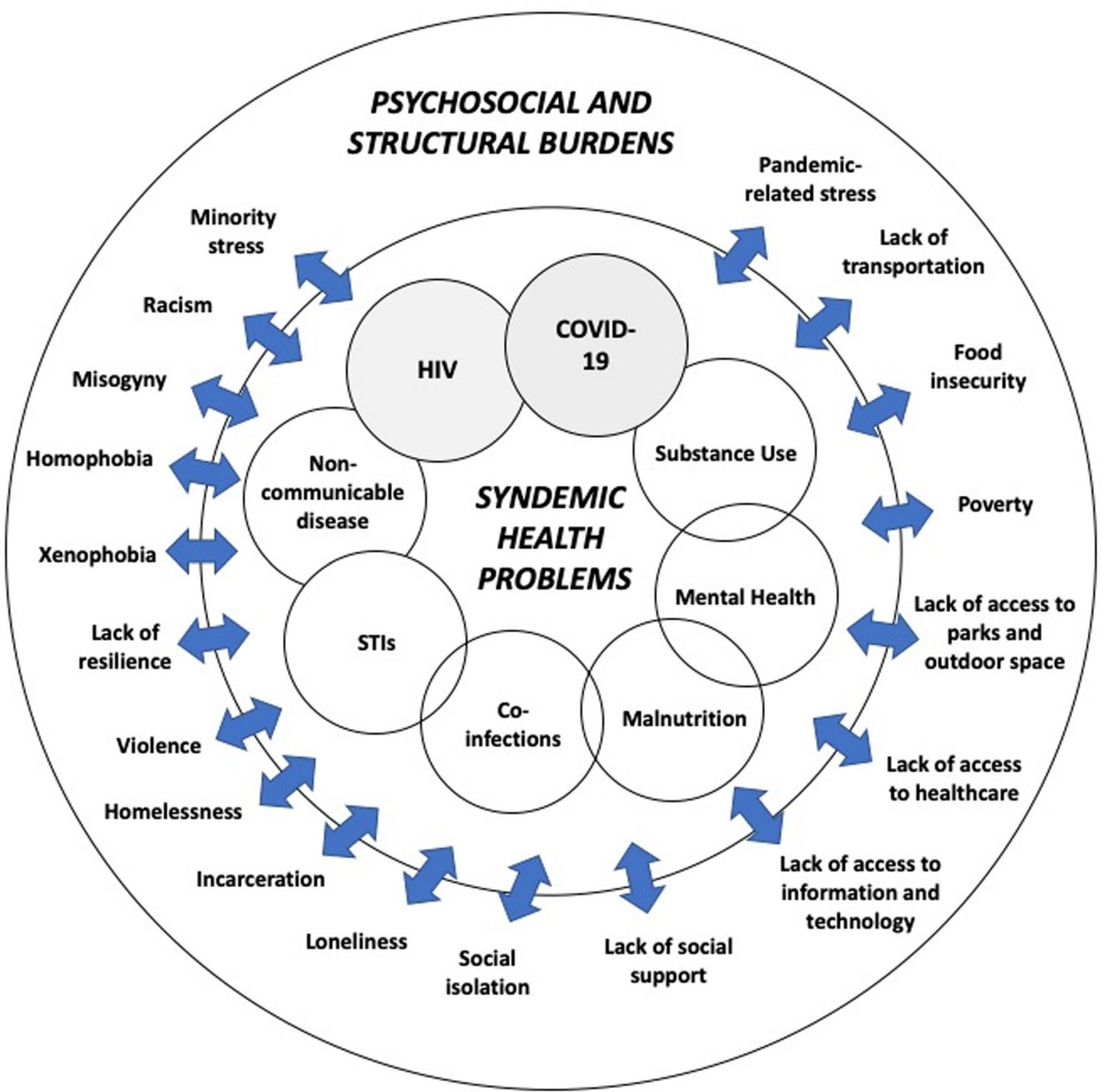

Fig. 1 A syndemic conceptualization of HIV \& COVID-19 co-infection in people living with HIV

health [39]. Thus, if we are to address COVID-19 infection for vulnerable populations including PLWH effectively, these matters must be brought to bear. Such drivers may include political and human rights determinants [49], including but not limited to state-sanctioned discrimination [4]. These factors are deemed to create the biological vulnerabilities that are noted in communities of color, particularly those populations where the experience of such stressors is heightened. In this view, it is understandable why migrants, people with criminal justice histories, the poor, and those who do not identify as White, heterosexual, or cisgender are more susceptible to disease states. Additionally, food insecurity is a factor that contributes to this syndemic [5]. Food insecurity has been associated with increased HIV transmission risk, poor clinic attendance, poor ART adherence, poor immunological and virologic responses, lower efficacy of ART, and high mortality [50]. The COVID-19 pandemic has created more heightened food insecure states for all populations, including PLWH, therefore exacerbating these burdens. 


\section{Healthcare Access and COVID-19 in People Living with HIV}

PLWH require regular engagement with the healthcare system to maintain viral suppression, which provides optimal clinical benefits and drastic reductions in HIV transmission [51, 52]. At the IDP in Newark, NJ, adherence to appointment visits has been associated with a higher likelihood of viral suppression. ART implementation and consistent adherence have improved the long-term health outcomes among PLWH, but they are vulnerable if interruptions in treatment occur due to the COVID-19 pandemic. Interactions with health providers, access to medications, and adherence are undermined by physical distancing imposed by many states and municipalities. Findings drawn from 9/11 indicate that in times of crisis, adherence to ART may be severely compromised for PLWH, creating an additional level of concern [53]. It is unclear if telemedicine will yield the same associations between visits and viral load suppression.

In the Wuhan region of China, reports indicate PLWH have struggled to access ART during the COVID-19 outbreak due to the stigma and discrimination surrounding the HIV/AIDS epidemic in the country [54]. While this has not been reported to date in the United States, there are growing concerns around overall prescription drug shortages due to drop-offs in production in China and India [55]. If PLWH cannot access ART, their viremia will likely increase [56], leading to lower CD4 T-cell counts [57], an increased risk of developing opportunistic infections [58], and an increased risk of HIV transmission to others. As such, it is imperative PLWH remain engaged with their primary and HIV healthcare providers amidst the COVID-19 pandemic to ensure consistent access to HIV-related care and treatment.

One way to ensure steady access to care is through telemedicine- a mode in which medical practitioners can provide care to their patients over the phone or through video conferencing $[59,60]$. This healthcare delivery mode has been successful with some sub-populations of PLWH, including women and smokers [60]. However, in light of the COVID-19 pandemic, it is likely that economic, geographic inequities, and the digital divide will prevent some PLWH from accessing care via this route due to lack of necessary technology (e.g. computer, smartphones, etc.) or adequate internet access, especially among older PLWH [60-63].

\section{Conclusion}

As COVID-19 emerges in the population of PLWH, we must contextualize the health challenges that will emerge within a syndemic framework-one that is more of a conceptualization [17] than a theory per se that prescribes specific elements of the paradigm [39]. This framing also fully embraces the concept of pathogen-pathogen interaction, which is central to our understanding of HIV-COVID-19 co-infection [3]. To protect PLWH from COVID-19 and future pandemics, programming to address COVID-19 disease in light of the multiple mutually reinforcing health burdens faced by PLWH is imperative. While healthcare providers often attend to the biological, behavioral, and occasionally psychological drivers of health, public health focuses on the structural drivers of disease and disease surveillance, neither fully embraces the psychosocial burdens and stressors that diminish well-being as delineated in a conceptualization such as that of a syndemic [13]. Effective treatment for HIV-COVID-19 coinfection must be designed to address these viral interactions as well as the psychosocial burdens that both exacerbate co-infection and increase the likelihood of mortality.

Finally, it also must be noted that antiretroviral treatments, either in the form of ART for PLWH or the form of pre-exposure prophylaxis (PrEP), may bestow some protection against COVID-19 [30, 64]. In fact, at the IDP, many of the PLWH are not presenting with severe symptoms of COVID-19. If there is evidence to support this assertion, there must be ongoing vigilance to identify and treat HIV infections and actively maintain PLWH in treatment and care.

\section{References}

1. CDC. Coronavirus Disease 2019 (COVID-19) in People with HIV [Internet]. Centers for Disease Control and Prevention. 2020 [cited 2020 Mar 23]. Available from: https://www.cdc. gov/coronavirus/2019-ncov/specific-groups/hiv.html

2. Earnshaw VA, Smith LR, Chaudoir SR, Amico KR, Copenhaver MM. HIV stigma mechanisms and well-being among PLWH: a test of the HIV stigma framework. AIDS Behav. 2013;17(5):1785-95.

3. Singer M. Pathogen-pathogen interaction: a syndemic model of complex biosocial processes in disease. Virulence. 2010;1(1):10-8.

4. Halkitis PN, Moeller RW, Siconolfi DE, Storholm ED, Solomon TM, Bub KL. Measurement model exploring a syndemic in emerging adult gay and bisexual men. AIDS Behav. 2013; 17(2):662-73.

5. Halkitis PN, Kupprat SA, Hampton MB, Perez-Figueroa R, Kingdon M, Eddy JA, et al. Evidence for a syndemic in aging HIV-positive gay, bisexual, and other MSM: implications for 
a holistic approach to prevention and healthcare. Nat Resour Model. 2012;36(2):365-86.

6. Rodriguez-Penney AT, Iudicello JE, Riggs PK, Doyle K, Ellis RJ, Letendre SL, et al. Co-morbidities in persons infected with HIV: increased burden with older age and negative effects on healthrelated quality of life. AIDS Patient Care STDs. 2013;27(1):5-16.

7. Novel Coronavirus Pneumonia Emergency Response Epidemiology Team. The epidemiological characteristics of an outbreak of 2019 novel coronavirus diseases (COVID-19) in China. Zhonghua Liu Xing Bing Xue Za Zhi Zhonghua Liuxingbingxue Zazhi. 2020;41(2):145-51.

8. Zhou F, Yu T, Du R, Fan G, Liu Y, Liu Z, et al. Clinical course and risk factors for mortality of adult inpatients with COVID-19 in Wuhan, China: a retrospective cohort study. Lancet Lond Engl. 2020;395(10229):1054-62.

9. González-Guarda RM, Florom-Smith AL, Thomas T. A syndemic model of substance abuse, intimate partner violence, HIV infection, and mental health among Hispanics. Public Health Nurs Boston Mass. 2011;28(4):366-78.

10. Stall R, Friedman M, Catania JA. Interacting Epidemics and Gay Men's Health: A Theory of Syndemic Production among Urban Gay Men [Internet]. Unequal Opportunity. Oxford University Press; [cited 2020 Apr 6]. Available from: https://www.oxfordscho larship.com/view/10.1093/acprof:oso/9780195301533.001.0001/ acprof-9780195301533-chapter-9

11. Halkitis PN, Kapadia F, Bub KL, Barton S, Moreira AD, Stults $\mathrm{CB}$. A Longitudinal investigation of syndemic conditions among young gay, bisexual, and other MSM: The P18 Cohort Study. AIDS Behav. 2015;19(6):970-80.

12. Halkitis PN. Reframing HIV prevention for gay men in the United States. Am Psychol. 2010;65(8):752-63.

13. Singer M, Bulled N, Ostrach B, Mendenhall E. Syndemics and the biosocial conception of health. Lancet Lond Engl. 2017;389(10072):941-50.

14. National Minority AIDS Council. Continuing the Advance Against HIV/AIDS. 2014.

15. Trust for America's Health. Addressing the Social Determinants of Health Inequities Among Gay Men \& Men Who Have Sex With Men [Internet]. tfah. [cited 2020 Apr 6]. Available from: https://www.tfah.org/report-details/addre ssing-the-social-deter minants-of-health-inequities-among -gay-men-men-who-have-sex-with-men/

16. Singer M, Bulled N, Ostrach B. Syndemics and human health: implications for prevention and intervention. Ann Anthropol Pract. 2012;36(2):205-11.

17. Singer M, Clair S. Syndemics and public health: reconceptualizing disease in bio-social context. Med Anthropol Q. 2003; 17(4):423-41.

18. Sundermann EE, Erlandson KM, Pope CN, Rubtsova A, Montoya J, Moore AA, et al. Current Challenges And Solutions In Research And Clinical Care Of Older Persons Living With HIV: Findings Presented at the 9th International Workshop on HIV and Aging. AIDS Res Hum Retroviruses. 2019;35(11-12):985-98.

19. Erlandson KM, Karris MY. HIV and aging: reconsidering the approach to management of comorbidities. Infect Dis Clin N Am. 2019;33(3):769-86.

20. Collaboration ATC. Survival of HIV-positive patients starting antiretroviral therapy between 1996 and 2013: a collaborative analysis of cohort studies. Lancet HIV. 2017;4(8):e349-e356356.

21. Brooks JT, Buchacz K, Gebo KA, Mermin J. HIV infection and older Americans: the public health perspective. Am J Public Health. 2012;102(8):1516-26.

22. Deeks SG. HIV infection, inflammation, immunosenescence, and aging. Annu Rev Med. 2011;62:141-55.

23. Duffau P, Ozanne A, Bonnet F, Lazaro E, Cazanave C, Blanco P, et al. Multimorbidity, age-related comorbidities and mortality: association of activation, senescence and inflammation markers in HIV adults. AIDS Lond Engl. 2018;32(12):1651-60.

24. Shah ASV, Stelzle D, Lee KK, Beck EJ, Alam S, Clifford S, et al. Global burden of atherosclerotic cardiovascular disease in people living with HIV. Circulation. 2018;138(11):1100-12.

25. Shiau S, Broun EC, Arpadi SM, Yin MT. Incident fractures in HIV-infected individuals: a systematic review and meta-analysis. AIDS Lond Engl. 2013;27(12):1949-57.

26. Heckman TG, Halkitis PN. Biopsychosocial aspects of HIV and aging. Behav Med Wash DC. 2014;40(3):81-4.

27. Guan W-J, Ni Z-Y, Hu Y, Liang W-H, Ou C-Q, He J-X, et al. Clinical characteristics of Coronavirus Disease 2019 in China. N Engl J Med. 2020. https://doi.org/10.1056/NEJMoa2002032.

28. Zhu F, Cao Y, Xu S, Zhou M. Co-infection of SARS-CoV-2 and HIV in a patient in Wuhan city, China. J Med Virol. 2020. https ://doi.org/10.1002/jmv.25838.

29. Guo W, Weng HL, Bai H, Liu J, Wei XN, Zhou K, et al. Quick community survey on the impact of COVID-19 outbreak for the healthcare of people living with HIV. Zhonghua Liu Xing Bing Xue Za Zhi Zhonghua Liuxingbingxue Zazhi. 2020;41(5):663-7.

30. Joob B, Wiwanitkit V. SARS-CoV-2 and HIV. J Med Virol. 2020 Mar 27;

31. Mendenhall E, Kohrt BA, Norris SA, Ndetei D, Prabhakaran D. Non-communicable disease syndemics: poverty, depression, and diabetes among low-income populations. Lancet Lond Engl. 2017;389(10072):951-63.

32. Fang L, Karakiulakis G, Roth M. Are patients with hypertension and diabetes mellitus at increased risk for COVID-19 infection? Lancet Respir Med. 2020;8(4):e21.

33. CDCMMWR. Severe outcomes among patients with Coronavirus Disease 2019 (COVID-19)—United States, February 12-March 16, 2020. MMWR Morb Mortal Wkly Rep. 2019;69:343-6.

34. CDC. HIV Continuum of Care (2017) [Internet]. 2019 [cited 2020 Mar 23]. Available from: https://www.cdc.gov/nchhstp/newsr oom/2017/HIV-Continuum-of-Care.html

35. Mimiaga MJ, O'Cleirigh C, Biello KB, Robertson AM, Safren SA, Coates TJ, et al. The effect of psychosocial syndemic production on 4-year HIV incidence and risk behavior in a large cohort of sexually active men who have sex with men. J Acquir Immune Defic Syndr. 1999;68(3):329-36.

36. Dolder CR, Patterson TL, Jeste DV. HIV, psychosis and aging: past, present and future. AIDS Lond Engl. 2004;18(Suppl 1):S35-42.

37. Do AN, Rosenberg ES, Sullivan PS, Beer L, Strine TW, Schulden JD, et al. Excess burden of depression among HIV-infected persons receiving medical care in the united states: data from the medical monitoring project and the behavioral risk factor surveillance system. PLoS ONE. 2014;9(3):e92842.

38. Bing EG, Burnam MA, Longshore D, Fleishman JA, Sherbourne $\mathrm{CD}$, London AS, et al. Psychiatric disorders and drug use among human immunodeficiency virus-infected adults in the United States. Arch Gen Psychiatry. 2001;58(8):721-8.

39. Halkitis PN. Bridging the gap: public health psychology mends the chasm between clinical/medical care and public/population health. (In Press). Am Psychol. 2020;

40. Wang Y, Wang Z, Jia M, Liang A, Yuan D, Sun Z, et al. Association between a syndemic of psychosocial problems and unprotected anal intercourse among men who have sex with men in Shanghai, China. BMC Infect Dis. 2017;17(1):46.

41. Operario D, Yang M-F, Reisner SL, Iwamoto M, Nemoto T. Stigma and the Syndemic of Hiv-Related Health Risk Behaviors in a Diverse Sample of Transgender Women. J Community Psychol. 2014;42(5):544-57.

42. Singer MC, Erickson PI, Badiane L, Diaz R, Ortiz D, Abraham $\mathrm{T}$, et al. Syndemics, sex and the city: understanding sexually 
transmitted diseases in social and cultural context. Soc Sci Med 1982. 2006;63(8):2010-21.

43. Halkitis PN, Krause KD, Vieira DL. Mental health, psychosocial challenges and resilience in older adults living with HIV. Interdiscip Top Gerontol Geriatr. 2017;42:187-203.

44. Shippy RA, Karpiak SE. The aging HIV/AIDS population: fragile social networks. Aging Ment Health. 2005;9(3):246-54.

45. Perissinotto C, Holt-Lunstad J, Periyakoil VS, Covinsky K. A Practical approach to assessing and mitigating loneliness and isolation in older adults. J Am Geriatr Soc. 2019;67(4):657-62.

46. Halkitis P, D’Avanzo P, Stults C, Levy M, Krause K, Kupprat S, et al. Neurocognitive functioning in an urban clinic-based sample of adults ages 50 and older living with HIV. J HIVAIDS Soc Serv. 2016;15:1-22.

47. Cao J, Tu W-J, Cheng W, Yu L, Liu Y-K, Hu X, et al. Clinical Features and Short-term Outcomes of 102 Patients with Corona Virus Disease 2019 in Wuhan, China. Clin Infect Dis Off Publ Infect Dis Soc Am. 2020

48. Artiga S, Garfield R, Orgera K. Communities of Color at Higher Risk for Health and Economic Challenges due to COVID-19 [Internet]. The Henry J. Kaiser Family Foundation. 2020 [cited 2020 Apr 9]. Available from: https://www.kff.org/disparities-polic y/issue-brief/communities-of-color-at-higher-risk-for-health-andeconomic-challenges-due-to-covid-19/

49. Willen SS, Knipper M, Abadía-Barrero CE, Davidovitch N. Syndemic vulnerability and the right to health. Lancet Lond Engl. 2017;389(10072):964-77.

50. The Lancet Hiv null. The syndemic threat of food insecurity and HIV. Lancet HIV. 2020;7(2):e75.

51. Saag MS, Benson CA, Gandhi RT, Hoy JF, Landovitz RJ, Mugavero MJ, et al. Antiretroviral drugs for treatment and prevention of HIV infection in adults: 2018 Recommendations of the International Antiviral Society-USA Panel. JAMA. 2018;320(4):379-96.

52. Mugavero MJ, Amico KR, Horn T, Thompson MA. The state of engagement in HIV care in the United States: from cascade to continuum to control. Clin Infect Dis Off Publ Infect Dis Soc Am. 2013;57(8):1164-71.

53. Halkitis PN, Kutnick AH, Rosof E, Slater S, Parsons JT. Adherence to HIV medications in a cohort of men who have sex with men: impact of September 11th. J Urban Health Bull N Y Acad Med. 2003;80(1):161-6.

54. People living with HIV in Wuhan struggle to find medicine during coronavirus outbreak- $\mathrm{CNN}$ [Internet]. [cited $2020 \mathrm{Mar} 23$ ]. Available from: https://www.cnn.com/2020/03/13/health/coron avirus-china-hiv-wuhan-intl-hnk/index.html
55. Drug Shortage Concerns Are Top of Mind Amid COVID-19 Outbreak [Internet]. Pharmacy Times. [cited 2020 Mar 23]. Available from: https://www.pharmacytimes.com/news/drug-shortage-conce rns-are-top-of-mind-amid-covid-19-outbreak

56. Elvstam O, Medstrand P, Yilmaz A, Isberg P-E, Gisslén M, Björkman P. Virological failure and all-cause mortality in HIV-positive adults with low-level viremia during antiretroviral treatment. PLoS ONE. 2017;12(7):e0180761.

57. Gray ES, Madiga MC, Hermanus T, Moore PL, Wibmer CK, Tumba NL, et al. The neutralization breadth of HIV-1 develops incrementally over four years and is associated with CD4+ T cell decline and high viral load during acute infection. J Virol. 2011;85(10):4828-40.

58. Jones LE, Perelson AS. Transient viremia, plasma viral load, and reservoir replenishment in HIV-infected patients on antiretroviral therapy. J Acquir Immune Defic Syndr 1999. 2007;45(5):483-93.

59. Incorporating Telemedicine as Part of COVID-19 Outbreak Response Systems [Internet]. AJMC. [cited 2020 Apr 6]. Available from: https://www.ajmc.com/journals/issue/2020/2020-vol26 -n4/incorporating-telemedicine-as-part-of-covid19-outbreakresponse-systems

60. Marhefka S, Lockhart E, Turner D. Achieve research continuity during social distancing by rapidly implementing individual and group videoconferencing with participants: key considerations, best practices, and protocols. AIDS Behav. 2020

61. Gogia SB, Maeder A, Mars M, Hartvigsen G, Basu A, Abbott P. Unintended consequences of tele health and their possible solutions. Contribution of the IMIA Working Group on Telehealth. Yearb Med Inform. 2016;25(1):41-6.

62. Centers for Disease Control and Prevention (CDC). HIV: Economically Disadvantaged [Internet]. 2019 [cited 2020 Apr 6]. Available from: https://www.cdc.gov/hiv/group/poverty.html

63. Pew Research Center. Technology use among seniors [Internet]. Pew Research Center: Internet, Science \& Tech. 2017 [cited 2020 Apr 6]. Available from: https://www.pewresearch.org/inter net/2017/05/17/technology-use-among-seniors/

64. Martinez MA. Compounds with therapeutic potential against novel respiratory 2019 coronavirus. Antimicrob Agents Chemother. 2020

Publisher's Note Springer Nature remains neutral with regard to jurisdictional claims in published maps and institutional affiliations. 